\title{
Gamma interferon induces different keratinocyte cellular patterns of expression of HLA-DR and DQ and intercellular adhesion molecule-I (ICAM-I) antigens
}

\author{
C.E.M.GRIFFITHS, J.J.VOORHEES AND B.J.NICKOLOFF* \\ Departments of Dermatology and ^Pathology, University of Michigan Medical Center, Ann Arbor, Michigan, U.S.A.
}

Accepted for publication 30 June 1988

\section{SUMMARY}

With indirect immunofluorescence techniques we demonstrated that recombinant gammainterferon induced the expression of the class II antigens HLA-DR and HLA-DQ as well as intercellular adhesion molecule-I (ICAM-I) on normal, cultured human keratinocytes grown in low-calcium, serum-free medium. Each antigen displayed a distinctive cellular staining pattern. HLA-DR was strongly localized to perinuclear zones with intense cell surface expression; HLA-DQ displayed a perinuclear accentuation, but with minimal cell surface staining, and ICAM-I was strongly expressed in a diffuse cytoplasmic pattern with intense cell surface expression. Keratinocytes grown in medium supplemented with $10 \%$ fetal calf serum underwent differentiation, with a diminished expression of all three antigens as compared to those grown in low-calcium, serum-free medium.

These results confirm that gamma interferon can differentially regulate HLA-DR and HLADQ expression; that there are probably different biochemical metabolic pathways by which these three molecules are expressed on keratinocytes, and that the expression is also a function of the degree of keratinocyte differentiation. The strong cell surface expression of ICAM-I is suggested to be of major importance as the recognition molecule, by which $\mathrm{T}$ cells bind to gamma interferon exposed keratinocytes, and suggests an integral role for this molecule in epidermal lymphocyte trafficking.

The human class II major histocompatibility complex (MHC) antigens are coded for by three distinct loci on chromosome six: HLA-DR, HLA-DQ and HLA-DP. ${ }^{1}$ Unlike class I MHC

Correspondence: Brian J.Nickoloff, M.D., Ph.D., Department of Pathology, University of Michigan Medical Center, M4232 Medical Science I, I30I Catherine Street, Ann Arbor, MI 48109-0602, U.S.A.

This work was presented at The National Meeting of the Society for Investigative Dermatology, Inc., Washington D.C. April 27, 1988. 
antigens, which are ubiquitously expressed, class II antigens have a limited cellular distribution on human nucleated cells. ${ }^{2,3}$ HLA-DR expression on macrophages is necessary for antigen to be presented to $\mathrm{T}$ lymphocytes, ${ }^{4}$ and for induction of cytolytic T lymphocyte activity, ${ }^{5}$ and is involved in the autologous mixed lymphocyte reaction (AMLR). ${ }^{6}$ Much less is known about the functional significance of HLA-DQ. However, it has similar effects to HLA-DR and Gonwa $e t$ al. ${ }^{7}$ have shown it to be required for antigen presentation in the AMLR. In normal skin, both HLA-DR and HLA-DQ are found on the same cells, namely vascular endothelium, ${ }^{8}$ Langerhans cells ${ }^{9}$ and the acrosyringial epithelium. ${ }^{10}$ Under normal circumstances neither antigen is expressed by keratinocytes (KC). ${ }^{11}$ In diseased skin, particularly the inflammatory dermatoses, HLA-DR is commonly expressed by $\mathrm{KC}^{12}$ and has been related to the presence of intra-epidermal lymphocytes. ${ }^{13} \mathrm{HLA}-\mathrm{DQ}$ expression by $\mathrm{KC}$ is infrequent although it has been observed in cutaneous $\mathrm{T}$ cell lymphoma, lichen planus, ${ }^{14}$ Borrelia-induced skin disease,${ }^{15}$ and allergic and irritant contact dermatitis. ${ }^{16}$

Gamma interferon IFN- $\gamma$, induces HLA-DR expression on normal cultured human $\mathrm{KC}^{17}$ and direct intradermal injection of IFN $-\gamma$ will induce the appearance of HLA-DR on the overlying epidermal KC. ${ }^{18}$ However, IFN- $\gamma$ has not been demonstrated to induce HLA-DQ on normal cultured human $\mathrm{KC}^{19}$ or on $\mathrm{KCs}$ in a short-term organ culture system. ${ }^{11,20}$

Intercellular adhesion molecule-I (ICAM-I) is a cell surface glycoprotein of molecular weight $90-I_{4} \mathrm{kd}$ expressed by both haemopoeitic and non-haemopoeitic cells. ${ }^{21,22}$ It is involved in the regulation of lymphocyte-cell adherence mediated by lymphocyte functionassociated antigen-I (LFA-I) which is a ligand for ICAM-I. ${ }^{23}$ The adherence of resting and activated autologous and allogeneic $\mathrm{T}$ lymphocytes to IFN- $\gamma$ treated $\mathrm{KC}$ is blocked by antiLFA-I antibodies ${ }^{24.25}$ or anti-ICAM-I antibody, ${ }^{26}$ thus implying a role for ICAM-I in lymphocyte-KC interactions in the inflammatory dermatoses.

We have investigated the cellular distribution patterns of HLA-DR, HLA-DQ and ICAM-I in normal human cultured $\mathrm{KC}$ in serum-free and serum-supplemented medium and the effect of IFN $-\gamma$ on the expression of these antigens.

\section{METHODS}

\section{Preparation of keratinocyte cultures}

Samples of normal human skin were obtained from patients undergoing cosmetic surgery and single cell suspensions prepared according to the method of Liu and Karasek. ${ }^{27}$ Small, round, viable cells were seeded onto and grown in either $10 \mathrm{~cm}$ diameter Petri dishes (Lux Flow Laboratories, Inc) or Lab-Tek chamber slides (Miles Scientific, Inverhill, IL, U.S.A.) in either a serum-free $\mathrm{KC}$ growth medium containing low calcium ${ }^{28}$ (KGM, Clonetics, CO., San Diego, CA, U.S.A.) or Dulbecco's modified Eagle's medium (DMEM, Gibco Laboratories, Grand Island, NY) supplemented with $10 \%$ heat inactivated fetal calf serum (FCS, Gibco). Cells were maintained in a humidified incubator in $5 \% \mathrm{Co}_{2} / 95 \%$ air at $37^{\circ} \mathrm{C}$ and used after passage 3 .

Recombinant IFN $-\gamma$ (specific activity $=\mathrm{I} \cdot 7 \times \mathrm{IO}^{7} \mathrm{U} / \mathrm{mg}$; kindly provided by Dr M.Shepard, Genentech Inc., South Francisco, CA, U.S.A.) was used at a final concentration of $1200 \mathrm{U} / \mathrm{ml}$ and added to dishes or slides containing sub-confluent $\mathrm{KC}$, after which incubation was continued for 3 days at $37^{\circ} \mathrm{C}$.

Staining of keratinocyte for HLA-DR, HLA-DQ and ICAM-I

$\mathrm{KC}$ in Lab-Tek chamber slides were either fixed for $\mathrm{I} 5 \mathrm{~min}$ in acetone at $4 \mathrm{C}$ to permeabilize the cell membrane prior to staining, or were left unfixed. The $\mathrm{KC}$ monolayers were incubated for 25 
TABLE I. Monoclonal antibodies used in the study

\begin{tabular}{|c|c|c|c|}
\hline Antibody & Specificity & Isotype & Source \\
\hline TSI.I 6 & HLA-DR & $\gamma_{\mathbf{I}}$ & $\begin{array}{l}\text { Dr C.Clayberger, Stanford } \\
\text { University U.S.A. }\end{array}$ \\
\hline Leu ro & HLA-DQ & $\gamma_{\mathbf{I}}$ & $\begin{array}{l}\text { Becton Dickinson, Mountain View, } \\
\text { CA, U.S.A. }\end{array}$ \\
\hline RR-I I & ICAM-I & $\gamma_{\mathbf{I}}$ & $\begin{array}{l}\text { Dr T.Springer, Dana Farber } \\
\text { Cancer Institute, Boston, MA, U.S.A. }\end{array}$ \\
\hline OKT8 & CD8 & $\gamma_{\mathbf{I}}$ & Ortho Diagnostics, Raritan, NJ, U.S.A. \\
\hline
\end{tabular}

min on ice with $10 \mu \mathrm{g} / \mathrm{ml}$ of the panel of monoclonal antibodies listed in Table $\mathrm{x}$. OKT 8 was used as an isotype irrelevant control antibody. The cells were washed and then stained with I $\mu \mathrm{g}$ of fluorescein isothiocyanate (FITC)-conjugated anti-mouse IgG (Tago Inc., Burlingame, CA, U.S.A.). In order to investigate the possibility of anti-HLA-DQ antibody binding to HLA-DR antigen, which may have been altered after acetone fixation, ${ }^{29} \mathrm{KC}$ were stained directly with FITC-conjugated Leu ro (Becton Dickinson, Mountain View, CA, U.S.A.) for 25 min on ice and compared with $\mathrm{KCs}$ pre-incubated with TS I I 6 for $\mathrm{I}$ h on ice prior to staining with FITCconjugated Leu Io. The cells were examined using an Olympus BH-2 fluorescence microscope.

Cultured $\mathrm{KC}$ were trypsinized using $0.03 \%$ trypsin $/ 0.01 \%$ EDTA, an aliquot of $10^{6} \mathrm{KC}$ was stained as described above, and staining intensity and numbers of cells stained determined using fluorescence activated cell sorter (Epics 54I: Coulter Corp), as previously described. ${ }^{17}$

\section{RESULTS}

Induction of $H L A-D R, H L A-D Q$ and ICAM-I antigen expression by IFN- $\gamma$ Normal human KC grown in KGM in the absence of IFN- $\gamma$ did not express HLA-DR, HLADQ or ICAM-I. However, the addition of IFN- $\gamma(\mathrm{I} 200 \mathrm{U} / \mathrm{ml})$ induced distinct patterns of cellular expression for all three antigens. The staining patterns described combine the cell surface staining seen in the absence of fixation or permeabilization, and the intracellular staining seen after acetone treatment.

HLA-DR was localized to the perinuclear zone with intense cell suface expression (Fig. I), as has been observed previously. ${ }^{30}$ HLA-DQ showed perinuclear localization, but with minimal cell surface staining (Fig. 2). ICAM-I was strongly expressed in a diffuse cytoplasmic pattern with intense cell surface expression (Fig. 3). Using FITC-conjugated Leu to (anti-HLA-DQ) there was no observable inhibition of staining when the $\mathrm{KC}$ were pre-incubated with TS I. I6, suggesting that the Leu Io antibody was not binding to HLA-DR antigen (data not shown). This was also confirmed by the difference in the intensity of cell-surface staining between HLADR and HLA-DQ.

Effect of serum-supplemented medium on the IFN- $\gamma$-induced expression of $H L A-D R, H L A-D Q$ and ICAM-I

All three antigens were expressed less strongly on KC cultured DMEM $+10 \%$ FCS than on cells cultured in KGM. The cell surface expression of ICAM-I and HLA-DR was similar to that seen on KC cultured in KGM, but the intracellular staining was markedly reduced (data 


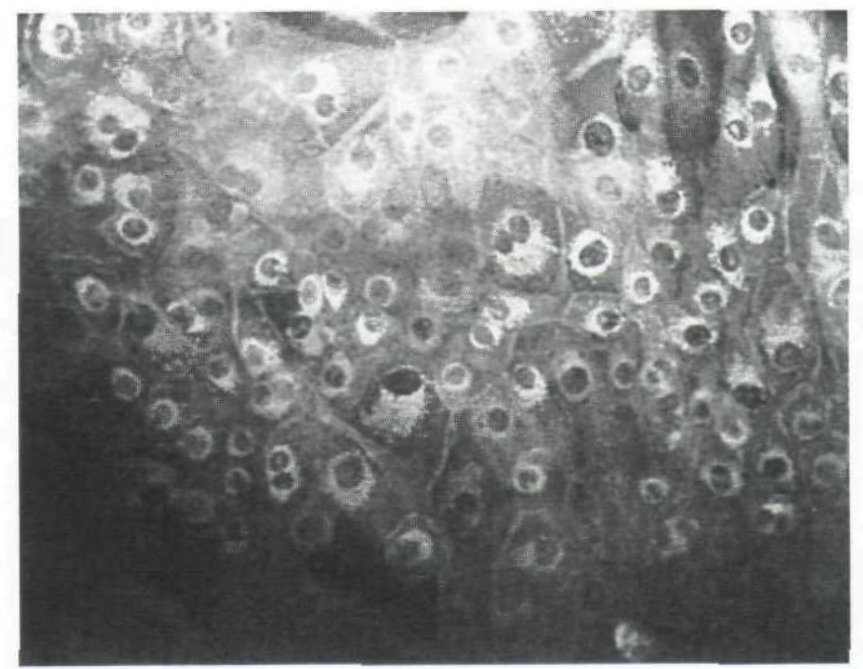

FIGURE I. IFN- $\gamma$-induced expression of HLA-DR on acetone-fixed keratinocytes showing perinuclear and intense cell surface staining (original $\times 150$ ).

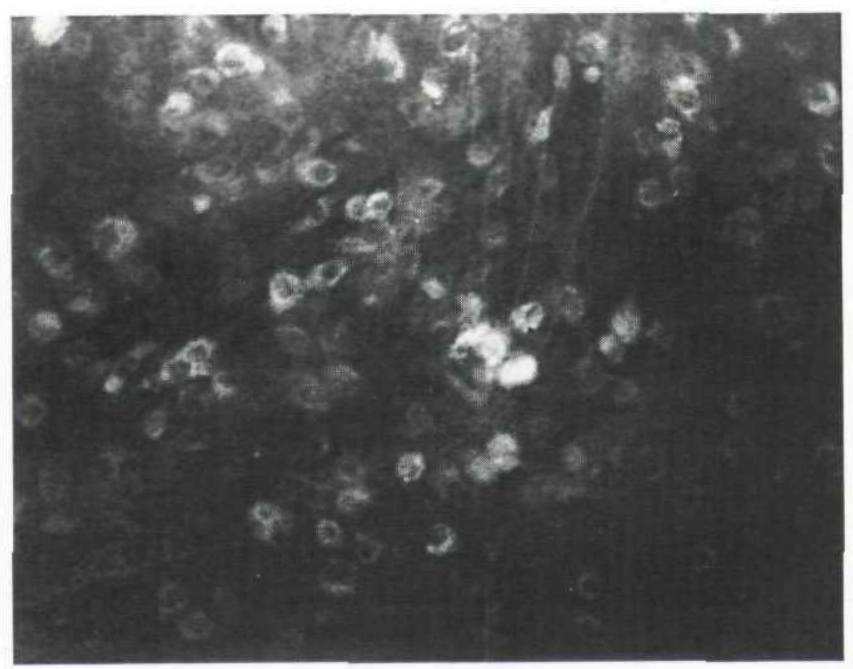

FIGURE 2. IFN- $\gamma$-induced expression of HLA-DQ on acetone-fixed keratinocytes showing perinuclear and minimal cell surface staining (original $\times$ I 50 ).

not shown). There was no cell surface expression of HLA-DQ on KC cultured in DMEM $+10 \%$ FCS and the intracellular staining was also markedly reduced.

Intensity of cell surface expression of HLA-DR, HLA-DQ and ICAM-I antigens using FACS analysis

After subtraction of OKT8 staining (which was used as the $\mathrm{IgG}_{1}$ isotype control) background values, the mean channel readings for the three antigens studied were: HLA-DQ: $18, H L A-D R$ : 52 and ICAM-I: 79. 


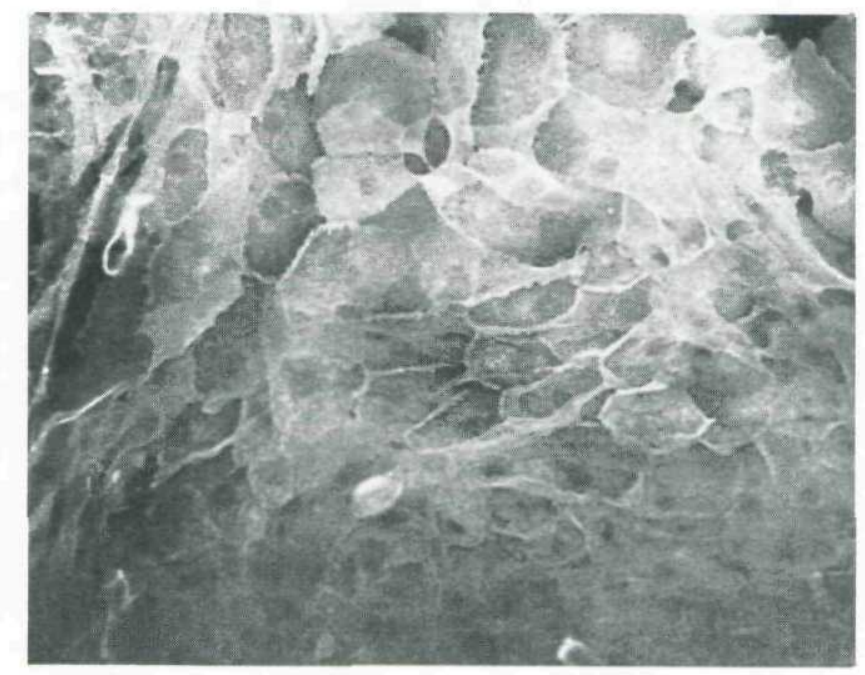

FIGURE 3. IFN- $\gamma$-induced expression of ICAM-I on acetone-fixed keratinocytes showing intense cell surface and diffuse cytoplasmic staining (original $\times 150$ ).

These values are for KC grown in KGM supplemented with IFN- $\gamma(\mathbf{I} 200 \mathrm{U} / \mathrm{ml})$ for 3 days. In the absence of IFN- $\gamma$, the mean channel readings were o for all three antigens, as well as for the OKT8 stained KC. It is important to use isotype controls because we have previously observed that IFN- $\gamma$ induces expression of Fc receptors in cultured KC. ${ }^{19}$ It should also be noted that the mean channel readings presented are on a log scale; thus the values represent a considerable degree of fluorescence intensity.

\section{DISCUSSION}

This study has demonstrated the ability of IFN- $\gamma$ to induce contrasting and distinctive cell surface and intracellular expression of HLA-DR, HLA-DQ and ICAM-I antigens in keratinocytes. The expression of these antigens was diminished by growing the $\mathrm{KC}$ in medium supplemented with serum. The induction of HLA-DQ by IFN- $\gamma$ is of interest as Basham et al. ${ }^{19}$ in a previous study, were unable to demonstrate this antigen on normal human $\mathrm{KC}$. This disparity can be explained by the fact that they cultured $\mathrm{KC}$ in DMEM $+10 \%$ FCS which we have shown to abrogate the cell surface expression of HLA-DQ. The observed reduction in IFN- $\gamma$-induced antigen expression in serum-supplemented medium was most probably a result of the greater degree of $\mathrm{KC}$ differentiation observed under these culture conditions.

The rarity of HLA-DQ expression on keratinocytes in vivo could well be because of the intracellular localization of this molecule which may not be detected by conventional staining techniques. It has been demonstrated that the cell surface expression of HLA-DR is five times greater than that of HLA-DQ, ${ }^{29}$ and shedding of the HLA-DQ molecule has also been postulated as a reason for its limited cell surface occurrence. ${ }^{31}$ Even in the inflammatory dermatoses, characterized by intense KC expression of HLA-DR, the concomitant appearance of HLA-DQ is unusual, and to date has only been observed in cutaneous T cell lymphoma, lichen planus, ${ }^{14}$ Borrelia-induced skin disease, ${ }^{15}$ and allergic and irritant contact dermatitis. ${ }^{16}$ This may be a marker of different $\mathrm{KC}$ function in these diseases, but is more probably a result of 
higher concentrations of IFN- $\gamma$ produced by dermal or intra-epidermal activated T lymphocytes in these particular dermatoses. An analogous situation has been observed in auto-immune thyroid disease where in class II antigen expression by thyrocytes HLA-DR is more commonly and intensely expressed than HLA-DQ. ${ }^{32}$ The same pattern is seen in cultured thyrocytes treated with IFN- $\gamma \cdot{ }^{32}$ Measurement of steady-state mRNA levels transcribed from different HLA-DQ loci may allow further identification of the genes upon which IFN- $\gamma$ acts in human KC. Further study of the regulation of HLA-DQ is required since one allele (HLA-DQ $\beta$ ) has recently been found to be associated with pemphigus vulgaris. ${ }^{33}$ Furthermore, HLA-DQ expression by lymphoid cells has been associated with antigen-specific suppression of the immune response. ${ }^{34}$ Since IFN- $\gamma$ treated $\mathrm{KCs}$ have also been observed to induce antigenspecific unresponsiveness, ${ }^{35}$ it will be of interest to determine whether such reactions are mediated via HLA-DQ.

The ability of IFN- $\gamma$ to induce ICAM-I expression on the surface of KC and the intense cell surface expression of this antigen is of major importance in the lymphocyte- $\mathrm{KC}$ adherence reaction in vitro ${ }^{24.25}$ and may also be relevant in many inflammatory dermatoses in vivo. ${ }^{20}$ It has been demonstrated that anti-LFA-I and anti-ICAM-I antibodies, but not anti-HLA-DR antibodies, inhibit the binding of $\mathrm{T}$ lymphocytes to IFN- $\gamma$-treated $\mathrm{KC}^{24-26}$ thus producing additional evidence that ICAM-I is involved in this process. The prominent cell-surface expression of this antigen by $\mathrm{KC}$ after IFN- $\gamma$ exposure supports this idea.

Thus, it is postulated that activated $T$ lymphocytes in the dermis induce ICAM-I expression on $\mathrm{KC}$ by means of IFN $-\gamma$ production. The present work extends our previous suggestion that IFN- $\gamma$ is the common molecule responsible for the expression of HLA-DR on KC in a variety of inflammatory dermatoses. ${ }^{36}$ ICAM-I expression of $\mathrm{KC}$ could promote lymphocyte-KC adherence reactions and the subsequent events leading to class II antigen induction on $\mathrm{KC}$, which may contibute to the pathophysiological changes observed in a variety of inflammatory dermatoses. ${ }^{37}$

\section{ACKNOWLEDGMENTS}

This work was partially supported by NIH Grant AR38957 (B.J.N.) and the Babcock Dermatological Endowment Fund. C.E.M.G. was supported by the British Association of Dermatologists Dowling Travelling Fellowship.

\section{REFERENCES}

I Giles RC, Capra JC. Structure, function and genetics of human class II molecules. In: Advances in Immunology, (Dixon FJ, ed.) London: Academic Press, 1985, 37: I-71.

2 Hammerling GJ. Tissue distribution of Ia antigens and their expression on lymphocyte sub-populations. Transplant Revi976, 30: 64-82.

3 Natali PG, Segatto O, Ferrone S et al. Differential tissue distribution and ontogeny of DC-I and HLA-DR antigens. Immunogenetics 1984; 19: 109-16.

4 Rosenthal AS, Shevach EM. Function of macrophages in antigen recognition by guinea-pig T lymphocytes. I. Requirement for histocompatible macrophages and lymphocytes. F Exp Med 1973; 138: II94-212.

5 Weinberger O, Herrman SH, Mescher MF et al. Cellular interactions in the generation of cytotoxic T-lymphocyte responses: role of Ia positive splenic adherent cells in presentation of H-2 antigen. Proc Natl Acad Sci USA I980; 77: $6091-95$.

6 Raff HV, Picker LJ, Stobo J. Macrophage heterogeneity in man: a sub-population of HLA-DR bearing macrophages required for antigen induced $\mathrm{T}$ cell activation also contains stimulators for autologous-reactive $\mathrm{T}$ cells. f Exp Med 1980; 152: 581-93. 
7 Gonwa TA, Picker LJ, Raff HV et al. Antigen-presenting capabilites of human monocytes correlates with their expression of HLA-DS, and Ia determinant distinct from HLA-DR. 7 Immunol 1983; 130: 706-II.

8 Natali PG, de Martino C, Quaranta V et al. Expression of Ia-like antigens in normal non-lymphoid tissues. Transplantation $1981 ; 3$ I : 75-3.

9 Stingl G, Tamaki K, Katz SI. Origin and function of epidermal Langerhans cells. Immunol Rev. I980; 53; I49-74.

Io Murphy GF, Shepard RS, Harrist TJ et al. Ultrastructural documentation of HLA-DR antigen reactivity in normal human acrosyringial epithelium. F Invest Dermatol r983; 81: 18I-3.

I I Messadi DV, Pober JS, Murphy GF. Effects of recombinant-interferon- $\gamma$ on HLA-DR and HLA-DQ expression by skin cells in short-term organ culture. Lab Invest $1988 ; 58: 6 \mathrm{I}-7$.

I2 Aubock H, Romani N, Grubauer G, Fritsch PI. HLA-DR expression on keratinocytes is a common feature of diseased skin. Br $\mathcal{F}$ Dermatol 1986; 114: 465-72.

13 Shiohara T, Moriya N, Tanaka Y et al. Immunopathologic study of lichenoid skin diseases: Correlation between HLA-DR positive keratinocytes or Langerhans cells and epidermotropic T cells. 7 Am Acad Dermatol 1987; 18: 6774.

I4 Volc-Platzer B, Groh V, Wolff K. Differential expression of class II alloantigens by keratinocytes in disease. $\mathcal{F}$ Invest Dermatol r987; 89: 64-8.

I5 Tjernlund U, Scheynius A, Asbrink E, Hovmark A. Expression of HLA-DQ antigens on keratinocytes in Borrelia spirochete-induced skin lesions. F Immunol r 986; 23: 383-8.

I6 Gawkrodger DJ, Carr MM, McVittie E et al. Keratinocyte expression of MHC class II antigens in allergic sensitization and challenge reactions and in irritant contact dermatitis. 7 Invest Dermatol 1987; 88: II-I6.

I7 Basham TY, Nickoloff BJ, Merigan TC, Morhenn VB. Recombinant gamma interferon induces HLA-DR expression on cultured human keratinocytes. F Invest Dermatol 1984; 83: 88-90.

I8 Nathan CF, Kaplan G, Lewis WR et al. Local and systemic effects of intradermal recombinant interferon-gamma in patients with systemic leprosy. $N$ Engl f Med I986; 31 5: 6-I I.

I9 Basham TY, Nickoloff BJ, Merigan TC, Morhenn VB. Recombinant gamma interferon differentially regulates class II antigen expression and biosynthesis on cultured normal human keratinocytes. F Interferon Res I985; 5: 23-7.

20 Griffiths CEM, Voorhees JJ, Nickoloff BJ. Characterization of intercellular adhesion molecule-I and HLA-DR expression in normal and inflamed skin: modulation by recombinant interferon- $\gamma$ and tumor necrosis factor. $\mathcal{F} \mathrm{Am}$ Acad Dermatol (in press).

2I Dougherty GJ, Murdoch S, Hogg N. The function of human intercellular adhesion molecule-I (ICAM-I) in the generation of an immune response. Eur f Immunol 1988; 18: 35-9.

22 Dustin ML, Rothlein R, Bhan AKet al. Induction by IL-1 and interferon- $\gamma$ : Tissue distribution, biochemistry, and function of a natural adherence molecule (ICAM-I). F Immunol 1986; 137: 245-54.

23 Marlin SD, Springer TA. Purified intercellular adhesion molecule-I (ICAM-I) is a ligand for lymphocyte functionassociated antigen-I (LFA-I). Cell $1987 ;$ 5r: 813-r9.

24 Nickoloff BJ, Lewinsohn D, Butcher EC et al. Recombinant gamma interferon increases the binding of peripheral blood mononuclear leukocytes and a leu- $3^{+} \mathrm{T}$ lymphocyte clone to cultured keratinocytes and to a malignant cutaneous squamous cell carcinoma line that is blocked by antibody against the LFA-I molecule. F Invest Dermatol 1988; 90: $17-22$.

25 Nickoloff BJ, Mitra RS. Phorbol treatment enhances binding of mononuclear leukocytes to autologous and allogeneic gamma interferon treated keratinocytes which is blocked by anti-LFA-I monoclonal antibody. $\mathcal{F}$ Invest Dermatol r 988 ; 90: 684-9.

26 Dustin ML, Singer KH, Tuck DT, Springer TA. Adhesion of T lymphoblasts to epidermal keratinocytes is regulated by interferon- $\gamma$ and is mediated by intercellular adhesion molecule-I (ICAM-I). $\mathcal{F}$ Exp Med I988; 167: $1323-40$.

27 Liu SC, Karasek M. Isolation and growth of adult human epidermal keratinocytes in cell culture. 7 Invest Dermatol 1978; 71: 157-62.

28 Boyce ST, Ham RG. Calcium regulated differentiation of normal human epidermal keratinocytes in chemically defined clonal culture and serum-free serial culture. F Invest Dermatol 1983; 81 (Suppl.): 33-40.

29 Chen Y-X, Evans RL, Pollack MS et al. Characterization and expression of the HLA-DC antigens defined by antiLeu 10. Hum Immunol 1984 ; $10: 22 \mathrm{I}-35$.

30 Wikner NE, Huff JC, Norris DA et al.Study of HLA-DR in cultured human keratinocytes. F Invest Dermatol 1986 ; 87: $559-64$.

3I Capobinanchi MR, Ameglio F, Tosi R, Dolei A. Differences in the expression of HLA-DR, BR and DQ molecules in human cells treated with recombinant interferon gamma: comparison to other interferons. Hum Immunol 1985 ; 13: II. 
32 Todd I, Pujol-Borrell R, Abdul-Karim AS et al. HLA-D Subregion expression by thyroid epithelium in autoimmune thyroid diseases and induced in vitro. Clin Exp Immunol 1987; 69: 532-42.

33 Sinha AA, Brautbar C, Szafer F et al. A newly characterized HLA-DQ allele associated with pemphigus vulgaris. Science I988; 239: 1026-9.

34 Hirayama K, Matsusuita S, Kikuschi I et al. HLA-DQ is epistatic to HLA-DR in controlling the immune response to schistosomal antigen in humans. Nature 1987; 327: 426-30.

35 Gaspari A, Jenkins M, Katz SI. Induction of antigen-specific T cell unresponsiveness by $\mathrm{Ia}^{+}$keratinocytes. F Invest Dermatol 1988; 90: 562 .

36 Nickoloff BJ, Basham TY, Merigan TC, Morhenn VB. Keratinocyte class II histocompatibility antigen expression. Br f Dermatol 1985; 11 2: 373-4.

37 Nickoloff BJ. The role of gamma interferon in cutaneous trafficking of lymphocytes with emphasis on molecular and cellular adhesion events. Arch Dermatol (in press). 
This document is a scanned copy of a printed document. No warranty is given about the accuracy of the copy. Users should refer to the original published version of the material. 